\title{
KENYAMANAN TERMAL RUANG TERBUKA HIJAU RPTRA DI JAKARTA
}

\author{
Albertus Kevin Adrian a \\ aUniversitas Surya; F8 \& F9 Grand Serpong Mall Jalan MH. Thamrin Panunggangan Utara Pinang Tangerang Banten \\ 15143l; kevin.adriann@gmail.com
}

Info Artikel:

- Artikel Masuk: 02/03/2020

- Artikel diterima: 06/03/2020

- Tersedia Online: 30/03/2020

\begin{abstract}
ABSTRAK
Ruang terbuka hijau perkotaan memiliki fungsi yang vital. Penelitian ini bertujuan untuk mengetahui tingkat kenyamanan thermal Ruang Terbuka Hijau RPTRA di Jakarta. Ruang Publik Terpadu Ramah Anak di Kembangan Utara Jakarta Barat dan Sungai Bambu Jakarta Utara diambil sebagai sample dalam penelitian ini. Penelitian dilakukan dengan cara pengukuran keadaan termal RTH serta penyebaran kuisioner kepada pengunjung. Hasilnya adalah keduanya belum bisa mencapai kenyamanan termal menurut standar kenyamanan termal dari SNI dan PMV (Predicted Mean Vote). Perlu ada stategi design pada kedua RTH tersebut untuk meningkatkan kenyamanan thermal bagi pengguna.
\end{abstract}

Kata Kunci: Kenyamanan Thermal; Ruang Terbuka Hijau, RPTRA Jakarta

\begin{abstract}
Urban green open space has a vital function. This study discusses the thermal comfort of the RPTRA Green Open Space in Jakarta. Child Friendly Integrated Public Spaces in Kembangan, West Jakarta and Sungai Bambu, Nort Jakarta were taken as samples in this study. The study was conducted by measuring the thermal comfort of green open space and the distribution of questionnaires to visitors. No one can achieve thermal comfort in accordance with the thermal comfort standards of SNI and PMV (Predicted Mean Vote). There needs to be a strategic design in both green open spaces to increase thermal comfort for the user
\end{abstract}

Keyword: Thermal Comfort; Green Open Space; RPTRA Jakarta

\section{PENDAHULUAN}

Ruang Terbuka Hijau memiliki peran yang vital salah satunya adalah memberikan kenyamanan bagi warga kota. Ruang terbuka hijau adalah bagian dari ruang-ruang terbuka (open spaces) suatu wilayah perkotaan yang diisi oleh tumbuhan, tanaman, dan vegetasi (endemik, introduksi) guna mendukung manfaat langsung dan/atau tidak langsung yang dihasilkan oleh RTH dalam kota tersebut yaitu keamanan, kenyamanan, kesejahteraan, dan keindahan wilayah perkotaan tersebut (Bappeda Kota Yogyakarta, 2009).

Pengaplikasian taman kota adalah perwujudan dari ruang terbuka hijau. Taman kota merupakan salah satu elemen penyusun ruang kota yang dibutuhkan oleh masyarakat. Sebagai ruang terbuka, taman kota dipahami sebagai ruang yang berisi unsur-unsur alam dan pemandangan yang ditimbulkan oleh keragaman vegetasi, aktivitas, dan unsur-unsur buatan yang disediakan sebagai fasilitas sosial dan rekreasi, serta sebagai sumber pernapasan kota (Olmsted, 1997: 5).

Salah satu jenis taman kota yang diterapkan di Provinsi DKI Jakarta adalah RPTRA (Ruang Publik Terpadu Ramah Anak). RPTRA adalah taman yang didesain dengan konsep modern yang akan memiliki berbagai macam jenis pepohonan dan dilengkapi dengan sarana pendukung berupa sarana bermain, sarana olah raga, pendopo untuk belajar, dll (Jakarta Smart City, 2016). RPTRA merupakan contoh ruang terbuka hijau di lingkungan perkotaan yang paling memungkinkan untuk diaplikasikan dikarenakan lahan kota yang 
terbatas. Namun, kondisi termal dari RPTRA ini belum dianalisis terkait dengan kenyamanan penggunanya.

Dilakukan studi analisis di dua lokasi RPTRA yang ada di wilayah DKI Jakarta mengenai bagaimana penerapan taman kota dalam menghadirkan kenyamanan termal bagi penggunanya. Dua lokasi yang terpilih adalah RPTRA Kembangan, Jakarta Barat dan RPTRA Sungai Bambu, Tanjung Priok, Jakarta Utara dikarenakan faktor adanya massa bangunan, luas, serta fasilitas yang hampir sama.

\section{DATA DAN METODE (Arial, 11pt, Bold)}

\subsection{Tahap Pengumpulan Data}

Pengumpulan data ini dilakukan untuk mengetahui bagaimana kondisi aktual dari RPTRA yang telah ditentukan menjadi lokasi penelitian. Data yang diharapkan adalah data primer dan data sekunder.

Data primer didapatkan melalui pengamatan langsung di lokasi penelitian, pengukuran langsung terhadap suhu di beberapa kawasan, kuesioner, maupun wawancara kepada pengguna RPTRA. Data primer ini terdiri dari:
1. Suhu udara
2. Kelembaban udara
3. Kecepatan angin

Suhu udara dan kelembaban udara diukur dengan menggunakan alat environment meter Krisbow KW06-291 sedangkan kecepatan angin dan arah angin diukur dengan menggunakan thermo-anemometer Krisbow KW06-562. Alat ini dipergunakan secara manual untuk mengukur suhu udara, kelembaban udara, dan kecepatan angin.

Pengukuran dilakukan pada titik-titik yang telah ditentukan dan dilakukan secara bergantian dari titik satu ke titik lainnya. Oleh karena lokasi antara titik pengukuran berdekatan, selang waktu antar pengukuran dapat diminimalkan. Kegiatan pengukuran ini dilakukan mulai dari pukul 09.00 WIB hingga pukul 17.00 WIB.

Pengukuran manual ini dilakukan dengan memegang alat pada ketinggian $\pm 1,00$ meter dari permukaan tanah kemudian didiamkan hingga suhu udara dan kelembaban udara yang tertera pada alat tidak naik / turun lagi atau pada saat sudah ada kestabilan suhu udara. Dalam hal kecepatan angin, hasil pengukuran yang dicatat adalah rata-rata hasil pengukuran selama beberapa detik. Hasil yang kemudian didapat adalah suhu udara, kelembaban udara, dan kecepatan angin untuk untuk masingmasing jamnya.

Alat yang digunakan:

1. Environment Meter Krisbow KW06-291

2. Thermo Anemometer Krisbow KW06562

3. Laser Distance Meter

\subsection{Titik Sampel Pengukuran}

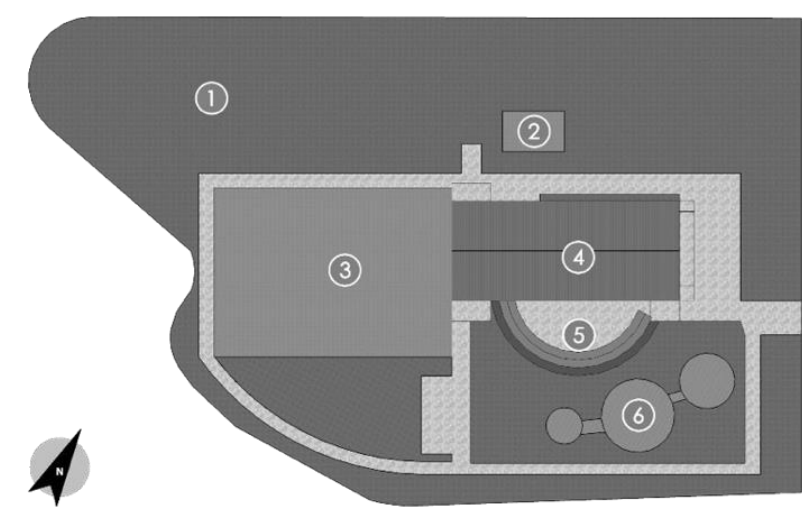

Gambar 1. Titik Sampel di RPTRA Kembangan Utara, Jakarta Barat (Hasil Analisa, 2017)

Titik sampel pengukuran diambil pada beberapa titik yang sering dipergunakan oleh pengunjung RPTRA. Titik sampel pada RPTRA Kembangan Utara, Jakarta Barat berada pada: 1. Kebun belakang, 2. Taman bermain belakang, 3. Lapangan futsal, 4. Teras samping ampiteater, 5. Ampiteater, 6. Taman bermain depan 


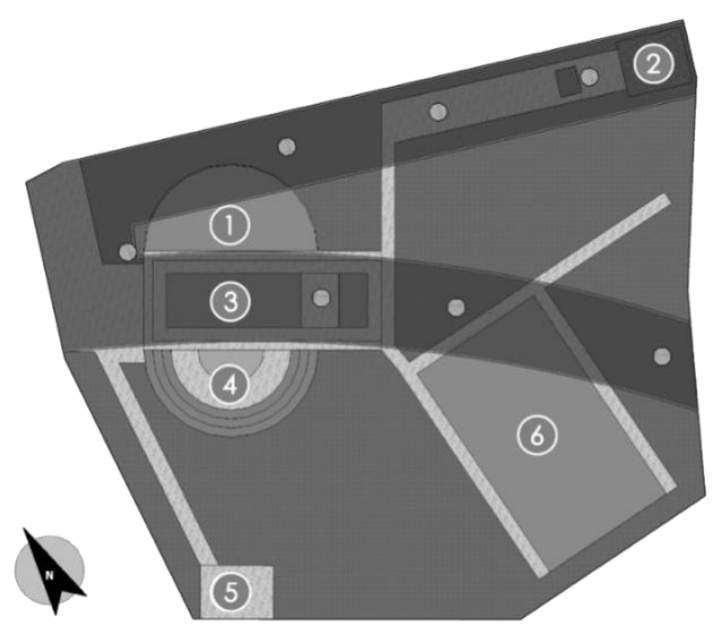

Gambar 2. Titik Sampel di RPTRA Sungai Bambu, Jakarta Utara (Hasil Analisa, 2017)

Titik sampel pada RPTRA Sungai Bambu, Tanjung Priok, Jakarta Utara berada pada: 1 . Taman Bermain Belakang, 2. Kebun Belakang, 3. Ruang Serbaguna, 4. Ampiteater, 5.Taman Bermain Depan 6. Lapangan Futsal

\section{HASIL DAN PEMBAHASAN}

\section{Suhu Udara}

Berikut merupakan grafik suhu udara di RPTRA Kembangan Kembangan, Jakarta Barat pada enam titik yang berbeda yang dilakukan pada pukul 09.00 WIB hingga pukul 17.00 WIB.

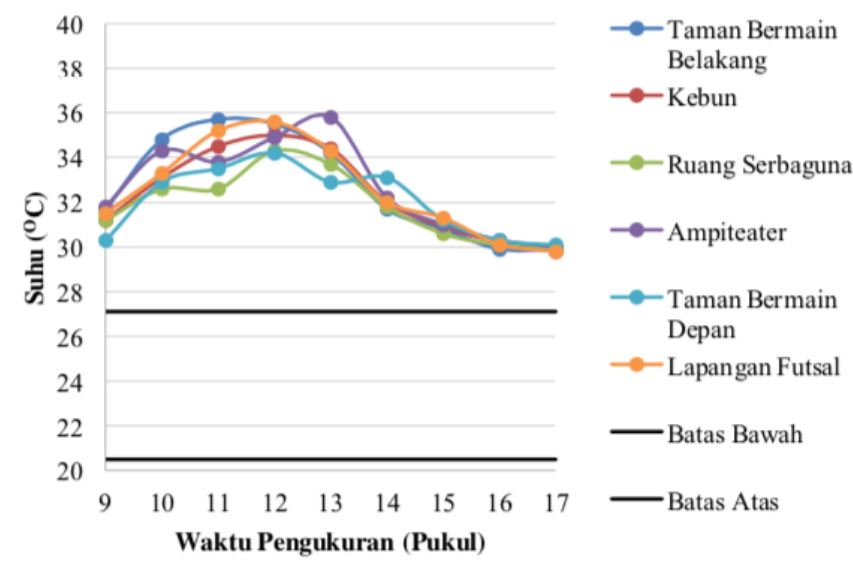

Gambar 3 Grafik Suhu Udara Hasil Pengukuran (Hasil Analisa, 2017)

Berdasarkan grafik di atas, dapat terlihat bahwa dari keenam titik pengukuran yang dilakukan selama waktu yang ditentukan, tidak ada suhu udara yang masuk ke dalam suhu nyaman menurut SNI maupun penelitian lainnya. Hal ini menunjukkan bahwa RPTRA Kembangan belum dapat mencapai kenyamanan termal berdasarkan standar dan penelitian.

\section{Kelembaban Udara}

Berikut merupakan grafik kelembaban udara di RPTRA Kembangan Utara, Jakarta Barat pada tujuh titik yang berbeda yang dilakukan pada pukul 09.00 WIB hingga pukul 17.00 WIB.

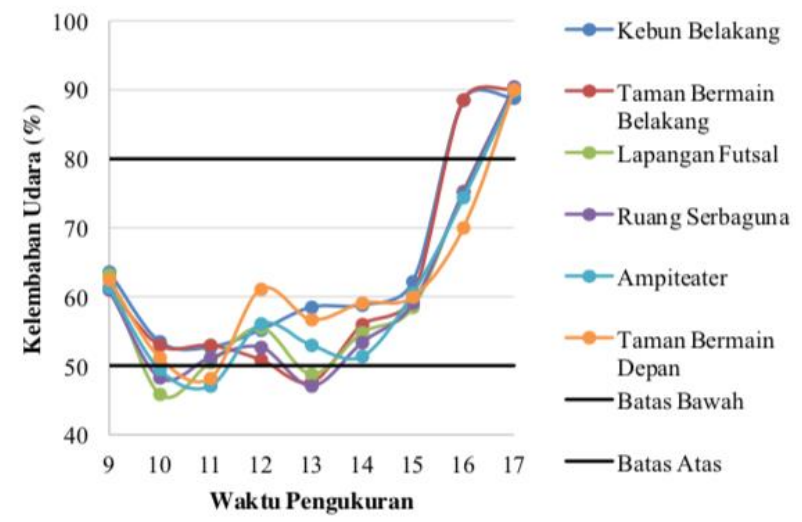

Gambar 4 Grafik Kelembaban Udara Hasil Pengukuran Grafik Kelembaban Udara Hasil Pengukuran di RPTRA Kembangan, Jakarta Barat pada Enam Titik Berbeda

Berdasarkan grafik di atas, dapat terlihat bahwa hampir keseluruhan titik pada tiap jam memperoleh nilai yang sesuai dengan standar kenyamanan termal. Kondisi kelembaban yang tidak sesuai dengan kriteria kenyamanan termal terjadi pada pukul 12.00 dan pukul 13.00 di beberapa titik. Kondisi ini dikarenakan panas yang cukup terik dan kondisi yang kering.

\section{Kecepatan Angin}

Grafik kecepatan angin di RPTRA Kembangan Utara, Jakarta Barat pada enam titik yang berbeda yang dilakukan pada pukul 09.00 WIB hingga pukul 17.00 WIB. 


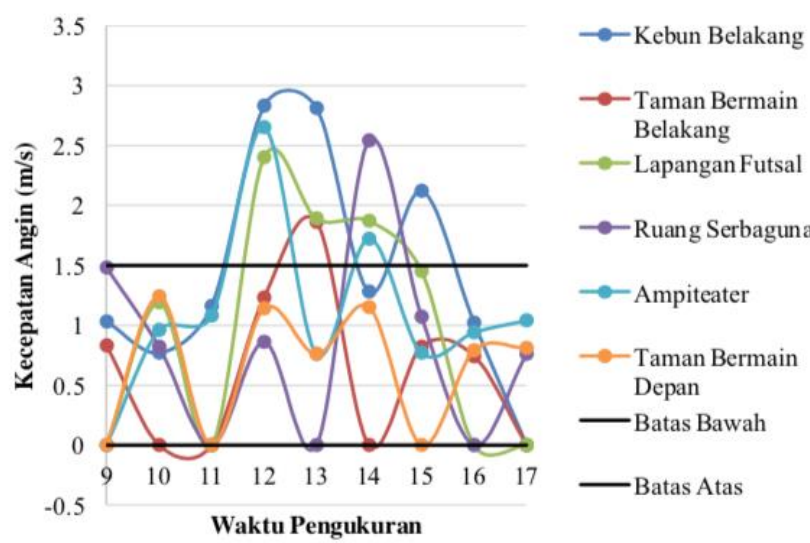

Gambar 5 Grafik Kecepatan Angin Hasil Pengukuran pada Enam Titik Berbeda di RPTRA Kembangan Utara, Jakarta Barat (Hasil Analisa, 2017)

Berdasarkan grafik di atas, kecepatan angin pada keenam titik masih pada kondisi nyaman. Hal ini dapat terlihat dari sedikitnya titik yang melebihi standar kenyamanan termal. Namun, seperti yang dapat terlihat bahwa kecepatan angin memiliki dinamika dari waktu ke waktu sehingga sulit untuk mendapatkan kondisi stabil.

\section{SIMPULAN}

Dari ketiga indikator kenyamanan termal meliputi dapat disimpulkan bahwa suhu udara, kecepatan usaha, dan kelembaban udara memenuhi standard kenyamanan termal baik dilihat berdasarkan standard SNI maupun standard PMV (Predicted Mean Vote) pada waktu pengukuran dari pukul 09.00 WIB hingga pukul 17.00 WIB baik di Ruang Terbuka Hijau RPTRA Kembangan Utara Kecamatan Jakarta Barat dan Sungai Bambu Kecamatan Jakarta Utara. Diperlukan stategi peningkatan kualitas kenyamanan termal pada RTH RPTRA di Jakarta agar lebih ramah anak.

\section{REFERENSI}

ASHRAE. (2013). Thermal Environmental Conditions for Human Occupancy. Retrieved 5 2, 2017, from ASHRAE: ashrae.org
Auliciems, A., \& Szokolay, S. (2007). Thermal Comfort. Queensland: International University of Queensland.

Bank, W. (2007). Berinvestasi untuk Indonesia yang Lebih Berkelanjutan. Jakarta: The World Bank Group.

Barakat, A., Ayad, H., \& El-Sayed, Z. (2017). Urban Design in Favor of Human Thermal Comfort for Hot Arid Climate Using Advanced Simulation Methods. Alexandria Engineering Journal, 1-11.

Bianpoen, dkk. (1989). Fungsi Taman dalam Kota. In Fungsi Taman dalam Kota (p. 7). Jakarta: PUSLIT Teknologi dan Permukiman UNTAR.

Carmona, M. (2003). Public Spaces - Open Spaces: The Dimensions of Urban Design. London: Architectural Press London.

Carmona, M. (2008). Public Space: The Management Dimension. New York: Routledge.

City, J. S. (2016). Kondisi RPTRA Bisa Dipantau Melalui Jakarta Smart City Portal. Retrieved 11 4, 2016, from Jakarta Smart City:

http://smartcity.jakarta.go.id/blog/37/kondi si-rptra-bisa-dipantau-melalui- jakartasmart-city-portal

Elnabawi, M. H., Hamza, N., \& Dudek, S. (n.d.). USE AND EVALUATION OF THE ENVIMET MODEL FOR TWO DIFFERENT URBAN FORMS IN CAIRO, EGYPT: MEASUREMENTS AND MODEL Simulations.

Herman. (2000). Pengaruh Naungan Terhadap Kenyamanan Termal Pemakai Jalur Pedestrian dan Selasar (Studi Kasus : Jalur Pedestrian dan Selasar Kampus Fakultas Teknik Universitas Indonesia). Depok: Fakultas Teknik Universitas Indonesia.

Huttner, S., Bruse, M., \& Dostal, P. (2010). Numerical Modeling of the Urban Climate - A Preview on Envi Met 4.0. Retrieved 11 2, 2016, from http://www.envi-met.net/

Kartawira, Y. (1989). Kriteria Kualitas Udara dan Bising. Jakarta: PUSLIT Teknologi dan Permukiman UNTAR.

Kemendagri. (2007). Peraturan Mendagri No. 1 Tahun 2007. 
Lippsmeier, G. (1997). Bangunan Tropis. Jakarta: Erlangga.

Nugroho, M. (2011). A Preliminary Study of Thermal Environment in Malaysia's Terraced House. Journal and Economic Engineering, 25-28.

Olgay, V. (1963). Design with Climate: Bioclimatic Approach to Architectural Regionalism. Princeton, New Jersey: Princeton University Press.

Olmsted, F. L. (1997). The Papers of Frederick Law Olmsted: Writings on Public Parks, Parkways, and Park Systems. Maryland: Johns Hopkins University Press.

Ragheb, A. A., El-Darwish, I. I., \& Ahmed, S. (2016). Microclimate and Human Comfort Considerations in Planning a Historic Urban Quarter. International Journal of Sustainable Built Environment, 156-167.

Taha, H., Sailor, D., \& Akbari, H. (1992). HighAlbedo Materials for Reducing Building Cooling Energy Use. California: Lawrence Berkeley Laboratory Report.

Yogyakarta, B. K. (2009). Rencana Aksi Ruang Terbuka Hijau. Yogyakarta. 